\title{
Exploratory Study on the Online Learning Understanding Based on Movement and Condition in Sitting Position
}

\author{
https://doi.org/10.3991/ijim.v15i18.24731 \\ Mazwani Binti Abdullah¹, Mohd Amran Bin Mohd Daril ${ }^{1(\mathbb{凶})}$, Mohammad \\ Ikbar Bin Abdul Wahab ${ }^{1}$, Khairanum Binti Subari ${ }^{1}$, Shahino Mah Bin Abdullah ${ }^{2}$ \\ ${ }^{1}$ Universiti Kuala Lumpur, Johor, Malaysia \\ ${ }^{2}$ University of Malaya, Kuala Lumpur, Malaysia \\ mamran@unikl.edu.my
}

\begin{abstract}
This research study the relationship between the understanding of online learning during Movement Control Order (MCO) due to pandemic Covid-19 and the movement condition through the sensor's parameters sensed by smartphone. The studies carried out to track the student's movement and conditions in sitting position while online class conducted and collect the data recorded by using smartphone sensors. The Apps AndroSensor is used to measure the Light intensity (lux), Orientation (axis x, y and z), Sound Level (dB) and Heart Rate (bpm). The understanding of online learning is measured using survey and questionnaire. The respondents that involves on this research are consists from different universities. Multiple Linear Regression was used to conclude the relationship between the parameters and the understanding of online learning. Total 60 students were involved in this study. Students that are selected has followed the criteria needed which are height, weight and age.
\end{abstract}

Keywords - orientation, accelerometer, sound level, hear rate, light of intensity

\section{$1 \quad$ Introduction}

Online learning is evolving as the new paradigm of modern education. It uses telecommunication tools to provide knowledge for lesson and practice. Online learning creates a high demand from business and institutes of higher institution. Other than that, it is a great in learning on modern society. During Movement Control Order (MCO) due to pandemic Covid-19, universities embark online learning for the student to attend the class without physical attendance either they stay in campus's hostel or off campus at their home. Online learning outside the classroom especially at home apparently will give different experience to the student because of different surrounding environment. Therefore, the student attention and focus during the online teaching may different compare to learning during physical classroom and there is a tendency of frequent movement while attending the online classroom. Based on this possible scenario of online leaning classroom, this study carried out to track the student's movement and 
conditions in sitting position while online class conducted and to find the relationship of these movement with the level of understanding of online learning during Movement Control Order (MCO) due to pandemic Covid-19.

\section{Revolution of online learning}

Salazar et al. [1] study the use of technology in learning activity that eventually contrbute to the revolution of online learning. As shown in Figure 1, this study stated that there are four type of learning method which are traditional learning method, E-learning, M-learning, and U-learning. Traditional learning method frontal teaching methods that mostly rely on technical teaching method and require face to face session. The E-learning method ideal for long-distance learning, and learners can learn when they have internet connectivity. The E-learning method require to have a computer and network to conduct this session. However, the E-learning decreases the interactions between teachers and students among other students. M-learning (Mobile learning) is a way to allow a student to study with a portable device such as smartphones from any location at any available time. However, it can make students anti-social so that it is known as a passive model of learning like e-learning. U-learning is defined as an active learning pattern compared with M-learning and enables students to gather knowledge from the learning environment through different sensor types.

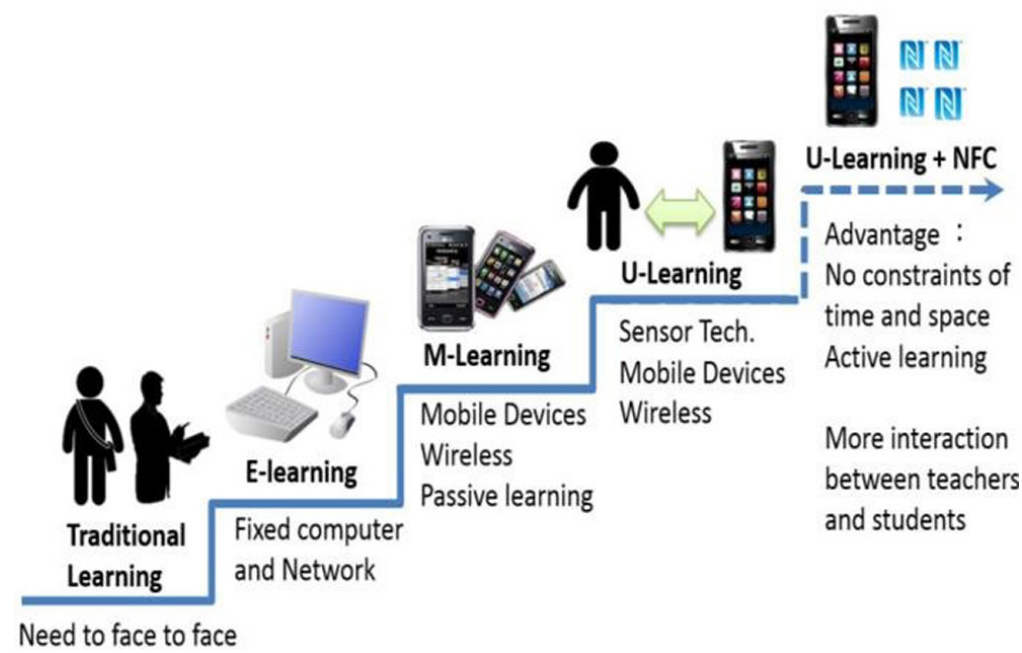

Fig. 1. Revolution of online learning [1]

\section{Sensor parameters}

Nowadays, smartphone consists a bunch of varieties and powerful sensors which are gives an opportunity for human interactions and connections, mainly in the most 
developed countries. In daily life, people bring the smartphone everywhere. The sensors in smartphone can give the information and news updated. Thus, promote a richer chances and experience for user through the development of the sensors days by days. Smartphone sensors have abilities to collect data and quantities hence create innovative applications. The access of exploring the smartphone recently have no limit. All the information, knowledge or anything that we need are also in our fingertips.

A sensor is a device, module or machine to detect any changes happen in its surrounding and transmit the input to other from the physical environment. The types of sensor could be light, heat, motion, humidity, light intensity or any other environmental phenomena. In broader benefit, sensors are used in daily life for instance touch-sensitive elevator buttons, lamp auto on in toilet and many others.

To track and record the student movement while attending the online classroom, the smartphone sensors is used. The Apps AndroSensor is used to measure the Light intensity (lux), Orientation (axis x, y and z), Sound Level (dB) and Heart Rate (bpm). Below Table 1 summarize the parameters used in this study.

Table 1. List of parameters

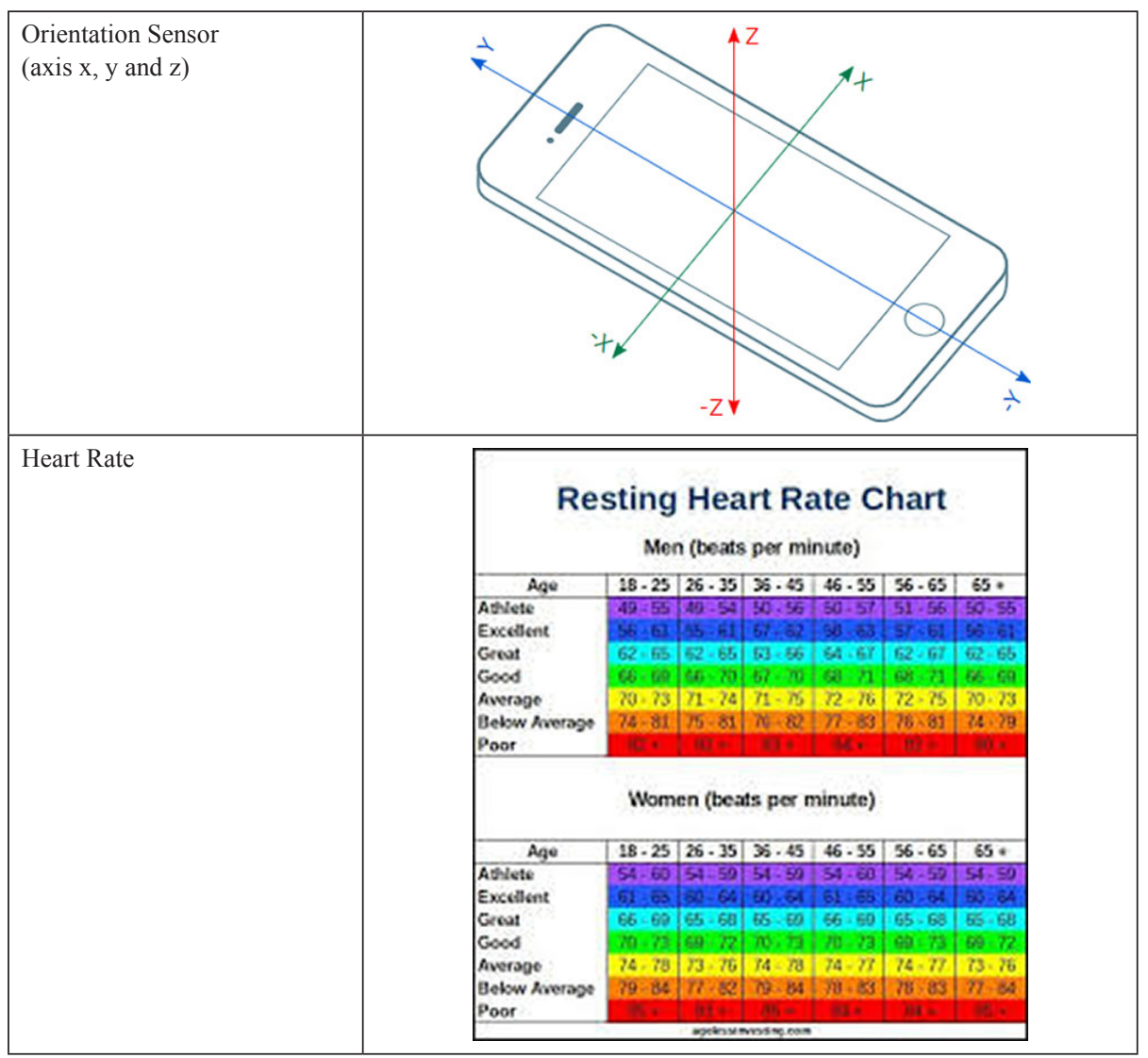

(Continued) 
Table 1. List of parameters (continued)

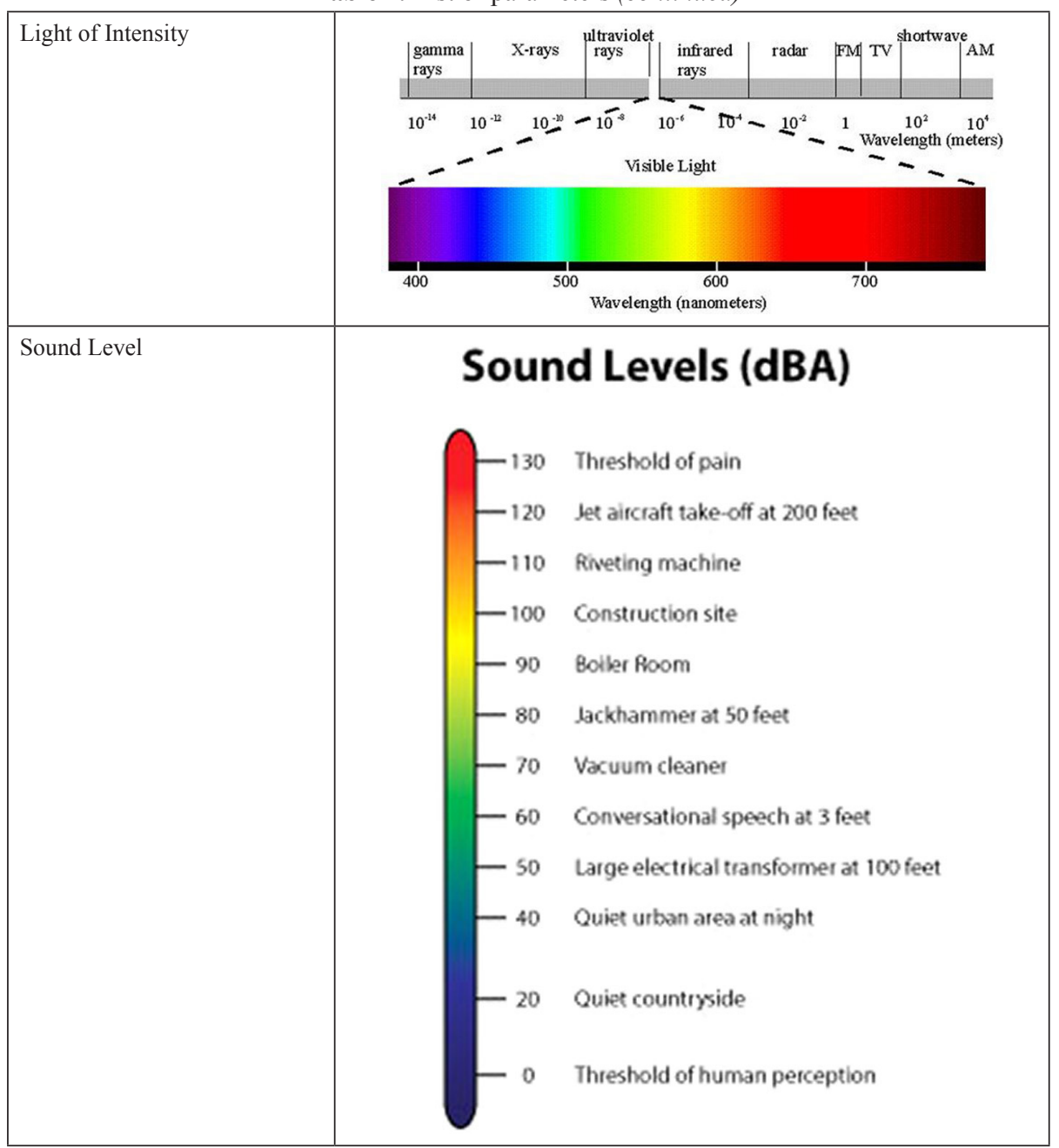

\section{$4 \quad$ Data collection}

The smartphone is wearable sensors in avoiding the need to acquire other sensor and suit the ideal ubiquitous monitoring devices [2], [3]. This study will show how the smartphone sensors can detect the total of human physical movement. By using the parameters accelerometers, gyroscope and magnetometers can know the total human movement [4]. The phone location is put in the pocket during the test conducted. The project was involved by students consists from different universities which are Universiti Kuala Lumpur (MITEC), Universiti Teknologi Malaysia, Skudai (UTM), Universiti Teknikal Malaysia, Melaka (UTEM) and UiTM Puncak Alam. The student 
requires to download and install apps sensor which is AndroSensor in their smartphone to detect and track their movement during online class [5].

Below flowchart in Figure 2 illustrates the system which is from start of the process until the end of the process. The flowchart helps students on the development of the process plus give the direction clearly in order to achieve the objectives of the research.

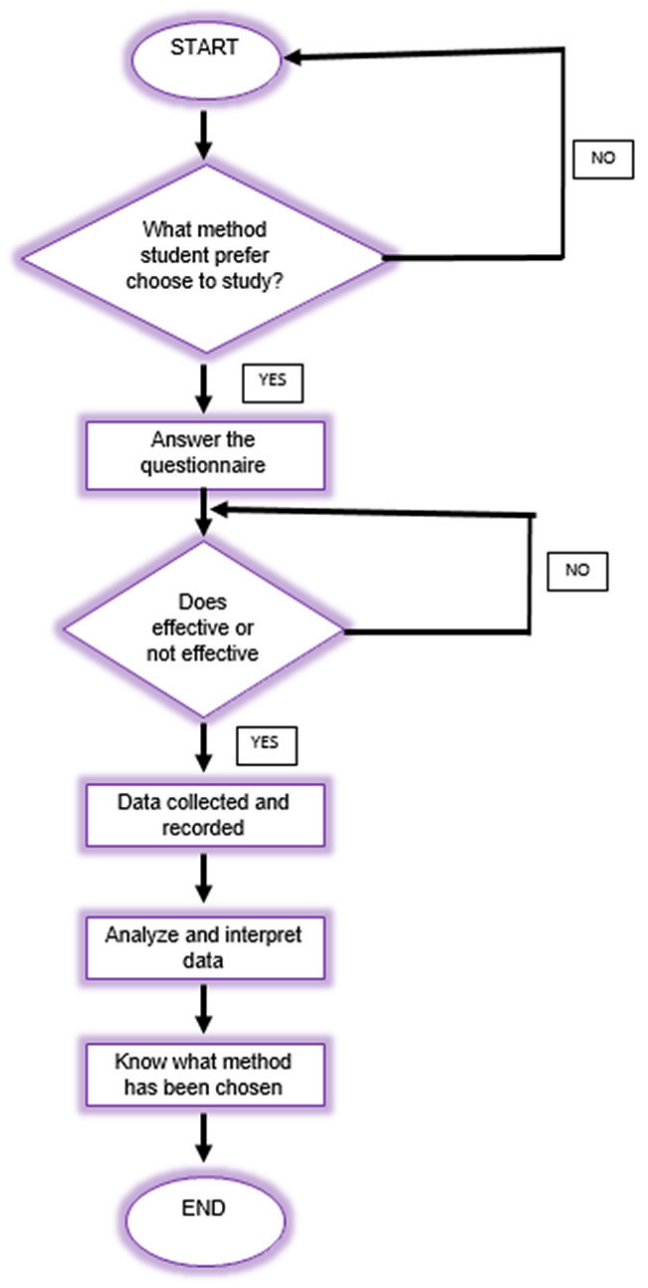

Fig. 2. Process flowchart

\section{$5 \quad$ Dependent variables and independent variables}

Below Figure 3 illustrate the relationship between movement of the student during online class and the level of understanding after attended the online learning. 


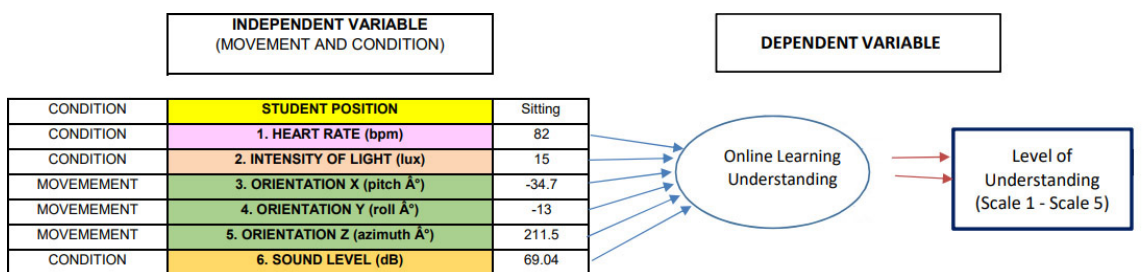

Fig. 3. Independent and dependent variables

The understanding of online learning is measured using survey and questionnaire. The respondents that involves on this research are consists from different universities. Total 60 students were involved in this study. Students that are selected has followed the criteria needed which are height, weight and age. Scale 1 To 5 as shown in below Table 2 is used in the questionnaire to measure the level of understanding.

Table 2. Understanding level

\begin{tabular}{|l|l|}
\hline 1 & $\begin{array}{l}\text { Has an elementary knowledge and skills } \\
\text { Poor level of skills }\end{array}$ \\
\hline 2 & $\begin{array}{l}\text { Has a basic knowledge and understanding } \\
\text { Limited level of skills }\end{array}$ \\
\hline 3 & $\begin{array}{l}\text { Has a sound knowledge and understanding } \\
\text { Adequate level of skills }\end{array}$ \\
\hline 4 & $\begin{array}{l}\text { Has thorough knowledge and understanding } \\
\text { Able to apply the skills in most situations }\end{array}$ \\
\hline 5 & $\begin{array}{l}\text { Has extensive knowledge and understanding } \\
\text { Can apply the skills in most and new situations and high competence }\end{array}$ \\
\hline
\end{tabular}

Regression analysis is statistical tehcnique for estimating the relatonship among variables which have reason and result relation. Main focus is to analyse the relationship between indepent variables and dependent variables. Multiple Linear Regression analysis is performed to conclude the relationship between the parameters and the understanding of online learning.

$$
Y i=\beta 0+\beta 1 \times i 1+\beta 2 \times i 2+\ldots+\beta p \times i p+\epsilon
$$

where, for $\mathrm{i}=\mathrm{n}$ observations:

yi $=$ dependent variable

$\mathrm{xi}=$ explanatory variables

$\beta 0=y$-intercept (constant term)

$\beta p=$ slope coefficients for each explanatory variable

$\epsilon=$ the model's error term (also known as the residuals)

\section{$6 \quad$ Result}

Below Table 3 tabulate the result of each student movement during attended the online class and their answer on the level of understanding after attended the online 
classroom. Based on this result there are 32 students were at level 3 of understanding, and 21 students at level 4 and 7 students at level 5. The heart rate, the light intensity and sound level data show that majority of the student were study in normal conditions with maximum heart rate is $115 \mathrm{bpm}$ and minimum $49 \mathrm{bpm}$, while maximum light intensity is 516 lux and minimum is 210 lux, and for maximum sound level is $70 \mathrm{db}$ and minimum is $38.6 \mathrm{db}$. For the student movement, majority of them move toward to the negative side for all direction X, Y, X. The student while study online learning and facing the computer screen the negative $X$ is show that they quite frequent moving to the left side, the negative $\mathrm{Y}$ show moving to backward and negative $\mathrm{Z}$ show the student moving to the downside.

Table 3. Result

\begin{tabular}{|c|c|c|c|c|c|c|}
\hline $\begin{array}{l}\text { Heart } \\
\text { Rate } \\
\text { (bpm) }\end{array}$ & $\begin{array}{c}\text { Light } \\
\text { Intensity } \\
\text { (lux) }\end{array}$ & $\begin{array}{l}\text { Orientation X } \\
\quad\left(\text { Pitch } \hat{A}^{\circ}\right)\end{array}$ & $\begin{array}{l}\text { Orientation Y } \\
\left(\text { Roll }^{\circ}\right)\end{array}$ & $\begin{array}{l}\text { Orientation } \mathbf{Z} \\
\left(\text { Azimuth } \hat{\mathbf{A}}^{\circ} \text { ) }\right.\end{array}$ & $\begin{array}{c}\text { Sound } \\
\text { Level } \\
\text { (db) }\end{array}$ & $\begin{array}{c}\text { Level of } \\
\text { Understanding }\end{array}$ \\
\hline 89 & 458.00 & -6.530 & 7.000 & -5.460 & 60.000 & 5 \\
\hline 90 & 250.00 & -5.460 & -4.000 & -4.000 & 45.865 & 4 \\
\hline 60 & 502.00 & -5.460 & -4.190 & -2.000 & 69.000 & 4 \\
\hline 92 & 432.00 & -4.190 & -6.530 & -4.000 & 49.998 & 5 \\
\hline 115 & 351.00 & -2.000 & -4.000 & -2.000 & 56.412 & 3 \\
\hline 97 & 348.00 & -9.120 & -2.000 & -4.000 & 41.572 & 4 \\
\hline 101 & 361.00 & -3.620 & -4.000 & -5.460 & 40.954 & 4 \\
\hline 60 & 516.00 & -5.460 & -4.000 & -4.190 & 38.600 & 5 \\
\hline 83 & 225.00 & -6.970 & -2.000 & -2.000 & 41.812 & 3 \\
\hline 66 & 210.00 & -4.000 & -4.000 & -6.970 & 43.216 & 4 \\
\hline 89 & 344.00 & -4.190 & -6.970 & -4.000 & 42.524 & 4 \\
\hline 103 & 230.00 & -4.000 & -4.000 & -6.530 & 41.861 & 5 \\
\hline 66 & 451.00 & -5.460 & -2.000 & -5.460 & 41.814 & 5 \\
\hline 89 & 461.00 & -4.190 & -4.000 & -5.460 & 42.785 & 5 \\
\hline 105 & 427.00 & -2.000 & -2.000 & -4.190 & 41.933 & 5 \\
\hline 103 & 320.00 & -9.120 & -5.460 & -2.000 & 48.709 & 3 \\
\hline 60 & 250.00 & -6.530 & -4.190 & -6.530 & 49.998 & 4 \\
\hline 68 & 310.00 & -6.530 & -2.000 & -3.620 & 56.412 & 4 \\
\hline 83 & 432.00 & -4.000 & -9.120 & -6.530 & 55.000 & 5 \\
\hline 51 & 351.00 & -2.000 & -3.620 & -6.970 & 55.000 & 5 \\
\hline 83 & 230.00 & -4.000 & -5.460 & -4.000 & 43.216 & 3 \\
\hline 82 & 361.00 & -4.000 & -6.970 & -4.000 & 57.000 & 4 \\
\hline 71 & 399.00 & -6.530 & -4.190 & -2.000 & 45.020 & 4 \\
\hline 103 & 225.00 & -4.000 & -5.460 & -4.000 & 50.320 & 3 \\
\hline 89 & 424.00 & -6.970 & -6.530 & -4.000 & 42.785 & 3 \\
\hline 86 & 344.00 & -5.460 & -4.000 & -2.000 & 45.865 & 3 \\
\hline
\end{tabular}

(Continued) 
Table 3. Result (continued)

\begin{tabular}{|c|c|c|c|c|c|c|}
\hline $\begin{array}{l}\text { Heart } \\
\text { Rate } \\
\text { (bpm) }\end{array}$ & $\begin{array}{c}\text { Light } \\
\text { Intensity } \\
\text { (lux) }\end{array}$ & $\begin{array}{c}\text { Orientation X } \\
\left(\text { Pitch } \hat{\mathbf{A}}^{\circ}\right)\end{array}$ & $\begin{array}{l}\text { Orientation Y } \\
\left(\text { Roll }^{\circ}\right)\end{array}$ & $\begin{array}{l}\text { Orientation } \mathbf{Z} \\
\text { (Azimuth } \hat{\mathbf{A}}^{\circ} \text { ) }\end{array}$ & $\begin{array}{c}\text { Sound } \\
\text { Level } \\
\text { (db) }\end{array}$ & $\begin{array}{c}\text { Level of } \\
\text { Understanding }\end{array}$ \\
\hline 50 & 453.00 & -4.000 & -2.000 & -4.190 & 48.709 & 4 \\
\hline 79 & 230.00 & -6.530 & -4.000 & -4.190 & 63.000 & 3 \\
\hline 82 & 237.00 & -4.000 & -6.530 & -2.000 & 56.412 & 3 \\
\hline 49 & 210.00 & -2.000 & -4.000 & -4.190 & 62.430 & 4 \\
\hline 103 & 320.00 & -4.000 & -3.620 & -4.000 & 58.000 & 3 \\
\hline 60 & 250.00 & -6.970 & -6.530 & -6.530 & 56.412 & 4 \\
\hline 89 & 310.00 & -3.620 & -3.620 & -4.000 & 60.000 & 4 \\
\hline 105 & 321.00 & 8.000 & -6.530 & -2.000 & 57.320 & 5 \\
\hline 103 & 351.00 & -2.000 & -6.970 & -4.000 & 61.000 & 4 \\
\hline 89 & 348.00 & -4.000 & -4.000 & -2.000 & 62.440 & 3 \\
\hline 83 & 440.00 & -6.530 & -6.530 & -5.460 & 55.940 & 3 \\
\hline 82 & 399.00 & -2.000 & -5.460 & -2.000 & 61.230 & 4 \\
\hline 89 & 225.00 & -6.970 & -5.460 & -4.000 & 55.230 & 4 \\
\hline 103 & 424.00 & -4.000 & -4.190 & -6.530 & 53.950 & 5 \\
\hline 76 & 344.00 & -4.190 & -4.190 & -4.000 & 56.412 & 5 \\
\hline 79 & 433.00 & -4.190 & -2.000 & -4.000 & 63.220 & 4 \\
\hline 65 & 439.00 & -4.000 & -9.120 & -6.970 & 59.420 & 4 \\
\hline 103 & 457.00 & -6.530 & -6.530 & -4.000 & 67.000 & 4 \\
\hline 85 & 427.00 & -5.460 & -4.000 & -4.190 & 60.000 & 3 \\
\hline 90 & 320.00 & -5.460 & -2.000 & -4.000 & 65.000 & 4 \\
\hline 89 & 250.00 & -4.190 & -4.000 & -6.530 & 56.412 & 4 \\
\hline 65 & 310.00 & -4.000 & -4.000 & -4.000 & 64.550 & 4 \\
\hline 70 & 432.00 & -4.190 & -2.000 & -2.000 & 58.000 & 5 \\
\hline 79 & 351.00 & -6.970 & -4.000 & -4.190 & 53.000 & 3 \\
\hline 101 & 348.00 & -4.190 & -4.000 & -2.000 & 70.000 & 3 \\
\hline 98 & 361.00 & -2.000 & -4.190 & -4.000 & 43.216 & 5 \\
\hline 78 & 399.00 & -4.190 & -2.000 & -2.000 & 64.320 & 4 \\
\hline 82 & 279.00 & -4.190 & -4.000 & -4.000 & 63.000 & 4 \\
\hline 89 & 424.00 & -2.000 & -6.530 & -6.970 & 64.000 & 3 \\
\hline 103 & 344.00 & -4.190 & -4.000 & -4.000 & 51.000 & 4 \\
\hline 85 & 453.00 & -4.190 & -2.000 & -6.530 & 50.000 & 4 \\
\hline 59 & 451.00 & -6.970 & -9.120 & -5.460 & 60.540 & 4 \\
\hline 105 & 429.00 & -6.530 & -6.970 & -5.460 & 58.420 & 3 \\
\hline 89 & 220.00 & -4.000 & -4.000 & -4.190 & 56.412 & 3 \\
\hline
\end{tabular}




\section{Conclusion}

One of the objectives for this study is to analyze the level of understanding of online learning during Movement Control Order (MCO) due to pandemic Covid-19. From the above result, due to normality test show that the data is not normal this study using median as an answer and thus the level of understanding for these students is at scale 4. Subsequent objective of the study is trying to identify the relationship between movement condition and sensor's parameters sensed by smartphone application. This study found the relationship by using Multiple Linear Regression with $43.25 \%$ of R-Square is shown as below.

Level of understanding $=5.239-0.00857$ Heart Rate +0.002736 Light (lux) + 0.1308 Orientation $X\left(\right.$ pitch $\left.\hat{A}^{\circ}\right)+0.0762$ Orientation $Y\left(\right.$ roll $\left.\hat{A}^{\circ}\right)-0.1230$ Orientation $\mathrm{Z}$ (azimuth $\hat{\mathrm{A}}^{\circ}$ ) -0.02127 Sound Level $(\mathrm{dB})$

The level of understanding when study through online leaning can be predicted through this Multiple Linear Regression formula. The application if this prediction is illustrated as below.

Heart Rate $=89 \mathrm{bpm}$

Light of Intensity $=458$ lux

Sensor Orientation $\mathrm{X}=-6.530$ pitch $\hat{A}$

Sensor Orientation $\mathrm{Y}=7.000$ roll $\hat{\mathrm{A}}$

Sensor Orientation $\mathrm{Z}=-5.460$ azimuth $\hat{\mathrm{A}}$

Sound Level $=60 \mathrm{~dB}$

Question: Based on above data what is the predicted level of understanding when study through online learning?

\section{Multiple Linear Regression formula:}

Level of understanding $=5.239-0.00857$ Heart Rate +0.002736 Light (lux) + 0.1308 Orientation X (pitch Â) +0.0762 Orientation Y (roll Â) -0.1230 Orientation $\mathrm{Z}$ (azimuth $\hat{\mathrm{A}}$ ) -0.02127 Sound Level $(\mathrm{dB})$

Substitute the data into the formula:

Level of understanding

$=5.239-0.00857(89)+0.002736(458)+0.1308(-6.530)+0.0762(7)-$ $0.1230(-5.460)-0.02127(60)$

$=4.47627+1.253088-0.854124+0.5334+0.67158-1.2762$

$=4.804014$

\section{Acknowledgement}

Thank you to Corresponding Authors which are Ts. Dr. Mohd Amran Bin Mohd Daril and Dr. Shahino Mah Bin Abdullah for the support and contribution to this 
research work. The research reported in this paper was supported by the Short-Term Research Grant (STRG) No UniKL/CoRI/str19057 awarded by Universiti Kuala Lumpur, Malaysia. Thanks to the respondents from UniKL MITEC, UTM and UTEM on the participation in this study.

\section{References}

[1] Salazar, L.H.A., Lacerda, T., Nunes, J.V., von Wangenheim, C.G. (2013) “A systematic literature review on usability heuristics for mobile phones. Int. J. Mob. Hum. Comput. Interact". (IJMHCI) 2013, 5, 50-61. https://doi.org/10.4018/jmhci.2013040103

[2] R. Want, (2010). "Iphone: Smarter than the Average Phone,". Pervasive Computing, IEEE, vol. 9, no. 3, pp. 6-9, 2010. https://doi.org/10.1109/MPRV.2010.62

[3] Khan N, Qureshi M, Mustapha I, Irum S, Arshad R. A systematic literature review paper on online medical mobile applications in Malaysia.

[4] Qureshi MI, Khan N, Raza H, Imran A, Ismail F. Digital Technologies in Education 4.0. Does it Enhance the Effectiveness of Learning? A Systematic Literature Review. International Journal of Interactive Mobile Technologies. 2021 Apr 1;15(4). https://doi.org/10.3991/ijim. v15i04.20291

[5] Mustapha I, Van NT, Shahverdi M, Qureshi MI, Khan N. Effectiveness of Digital Technology in Education During COVID-19 Pandemic. A Bibliometric Analysis. International Journal of Interactive Mobile Technologies. 2021 Aug 1;15(8). https://doi.org/10.3991/ijim. v15i08.20415

\section{Authors}

Mazwani Binti Abdullah, Quality Engineering Research Cluster, Quality Engineering Section, Universiti Kuala Lumpur, Malaysian Institute of Industrial Technology, 81750 Masai, Johor, Malaysia. E-mail: mazwani.abdullah@s.unikl.edu.my.

Mohd Amran Bin Mohd Daril, Quality Engineering Research Cluster, Quality Engineering Section, Universiti Kuala Lumpur, Malaysian Institute of Industrial Technology, 81750 Masai, Johor, Malaysia. E-mail: mamran@unikl.edu.my.

Mohammad Ikbar Bin Abdul Wahab, Quality Engineering Research Cluster, Quality Engineering Section, Universiti Kuala Lumpur, Malaysian Institute of Industrial Technology, 81750 Masai, Johor, Malaysia. E-mail: mikbar@unikl.edu.my.

Khairanum Binti Subari, Quality Engineering Research Cluster, Quality Engineering Section, Universiti Kuala Lumpur, Malaysian Institute of Industrial Technology, 81750 Masai, Johor, Malaysia. E-mail: khairanum@unikl.edu.my.

Shahino Mah Bin Abdullah, Low Dimensional Research Centre (LDMRC), Department of Physics, Faculty of Science, University of Malaya, 50603 Kuala Lumpur, Malaysia. E-mail: shahinomah@gmail.com.

Article submitted 2021-06-11. Resubmitted 2021-07-25. Final acceptance 2021-07-26. Final version published as submitted by the authors. 